\title{
Investigating the Behaviors of the Elementary School Students in Reference to Factors Associated with Daylight
}

\author{
Seied Majid Mofidi Shemirani \\ Assistant Professor, Department of Architecture, University of Science and Technology, Tehran, Iran \\ E-mail: maghaleh.isi@gmail.com
}

Gholam Hossein Memarian

Associate Professor, Department of Architecture, University of Science and Technology, Tehran, Iran

Shahnaz Pour Naseri

PhD Candidate, Department of Architecture, University of Science and Technology, Tehran, Iran

Hashem Hashem Nejad

Associate Professor, Department of Architecture, University of Science and Technology, Tehran, Iran

Vahid Vaziri

PhD Candidate, Department of Architecture, University of Science and Technology, Tehran, Iran

\begin{abstract}
There is no simple guide to human behavior which architects can use but recommendations rather an understanding of the principles of behavior and of man's interactions with buildings. To investigate the Behaviors of the Elementary School Students, the attitudes and behaviors towards the visual environment of three hundred and fifty primary school students were studied in eleven schools of varying design, with particular reference to factors associated with daylight and fenestration. The survey included social issues, personality characteristics of the primary school students and the varying visual characteristics of the buildings including photometric studies. Considerable proportions of students choose to work or sit near windows, the chief factor being the amount of daylight. View content, view out and nature are important. The most popular children occupy favored window places. Space and comfort both thermal and visual are important. Gender separation is natural.
\end{abstract}

Keywords: Behaviors, Elementary school, Students, Daylight

\section{Introduction}

Architects usually base their designs on incorrect assumptions about human behavior and that they are tending to assume that their individual experience depicts a common need. The author, as an architect, is aware of the issues, yet shares with most of his colleagues a desire to comprehend such needs and to use them in a creative method. Canter hints that there is no simple guide to human behavior which architects can use but recommendations rather an understanding of the principles of behavior and of man's interactions with buildings. (Tuaycharoen, 2007) Research on human use and attitude to buildings is a useful step in such a process. Several building types such as offices have been subject to such researches but elementary schools, although subjected to various researches, have had only little attention paid to the attitudes of their main users the children. Are the children too young to give a helpful opinion?

\section{Review of related literature}

Piaget has recognized steps of development in children's perceptive ability, a major stage arriving at eight or seven years, after which, he states, they can communicate a balanced view of their environments. (Laumann, 2001) This is supported by other researches even to the use of thermal rating scales. It may be derived that 
elementary school children are well able to meet the criteria for such research. There are other reasons why elementary schools should have this attention. Basic changes in educational methods have taken place in the last 25 years, changes so important as to find in Richmond's terms 'a teaching revolution'. Such changes in method, though by no means universal, however seem likely to be relatively permanent and they have far-reaching effect on the physical arrangements of elementary schools. Students become active and this applies also to educators, while child activity is seen as a result of interest. The changes seem to affect on more critical awareness of the surroundings of the building and their usage alters, often in unexpected ways. Important changes in the design of new schools have resulted, but is it certain that the changes in buildings compatible with the needs of the teachers and children when they have not been completely explored? How much help can be gained from the children in replying such questions? The logic of child-centered education hints the logic of child-centered design of their surroundings. (Brubaker, 1998) The simplest examination of schools using the new educating methods indicates that even in older, more formally designed schools the children use the buildings in completely a different way from the old pattern. Child place relates to activity rather than to the designated use of the space and the whole building is considered as potential usable space (children's choice of space usually seems astonishing to adults). Why not look at how the children actually use places in a range of schools and simultaneously measure and assess the environmental qualities of the spaces? If at the same time the children are asked for their ideas of the qualities of the spaces it may be possible to establish some basic views agree with the children, which, with interpretation, could serve the architects well. Such researches could be general, including all aspects of environment and use or could be particular to a few aspects. Of the latter the thermal aspects have been well investigated and of the former there are many studies by research organizations, central and local authorities. But in researches into fenestrations and lighting of schools the ideas are conflicting. (Dilouie, 1996) Earlier researches such as that by Larson use the scholastic performance of children as a measure of environmental effect, perhaps too coarse a measure. Attitudes of children to windows seem to vary with time and location. Some researchers report a priority of windowless schools while other researchers find the opposite. The wide variation of idea suggests that the visual environment needs more research, and especially, of the children's attitude to the daylight and windows they produce in the interiors. This research is particular rather than general and will attempt to eliminate other effects so far as possible. But while the investigation attempts to be particular, the process will necessitate some research in the fields of sociology, psychology, education and other disciplines. (Young, 2003) The general hypothesis is that elementary school children are attracted by daylight and by windows and this is reflected in their behavior. They prefer a high visual stimulus and are attracted by many of the aspects of windows including sunlight, daylight, view out, view content and visible activity. (Canter, 1974) In school they also have a social structure which may affect their behavior and attitudes. They can also be subject to personality characteristics which influence their reactions. It may be possible to relate children behavior to real measures of visual stimulus in the buildings. (Hopkinson, 1963)

\section{Method}

The research is based on the assumption that the children's attitude to their school environment and in particular to fenestration and daylight might be determined in the following ways. (1) By a study of children's behavior in terms of seating positions and movement adopted in schools especially in a free choice location with subsequent examination of the environmental qualities of the spaces used.

(2) By a questionnaire directed towards the environmental aspects of the buildings with more opportunity for free expression of idea.

(3) By examination of factors likely to effect of such behavior, in a process of elimination. Such factors would contain not only the characteristics of the spaces and their furnishings but also their personality characteristics and the social framework of the children in school.

\subsection{The sample}

The need to gain free expression of idea from the children as expressed by their behavior suggests selecting schools with informal educating systems such as 'integrated day' teaching where liberty of movement is common. All the education authorities in the northern half of Iran were investigated on this score and on certain other criteria, resulting in the selection of 11 elementary schools widely distributed over the area, comprising, one old school modernized, three old schools, one prefabricated unit and six post-1950 schools of various types, the sample averaging 30 children in each, aged 9-11 yr in mixed classes of girls and boys, in a total sample of about 350 children. So far as possible the rules for survey and choice of such a sample suggested by Oppenheim were observed. The enquiry took place in all schools during the same day by various teams following similar methods 
using standardized questionnaire. Environmental and Physical characteristics of the buildings were registered at further visits.

\subsection{Behavioral evidence}

In each elementary school two locations were identified. Location A in which the children had a reading task and the teacher was present in the normal manner. Location B in which the children were offered a free choice of position for a reading task and the teacher was absent. In both locations each child was identified and their location registered in plan on a standard $2400 \mathrm{~mm}$ grid on the floor. Furniture was considered in each case. Further movement wasn't allowed until the questionnaire was completed in location B.A pictorial record was provided. These records enabled subsequent research of each child's disposition and movement to be made.

\subsection{Attitudinal evidence}

All children in the survey answered a questionnaire containing open-ended and specific questions about their environment, some questions being designed to permit comparison with physical and photometric evidence about the spaces occupied. The questionnaire is based upon, Davies, Oppenheim and Davies, Hopkinson, Humphreys, and trial runs. Questions are in the following main classification. (Taylor, 1998)

(1) Factual-details of school and child: dislike/like of school, view, classroom, sun, colures.

(2) Open-ended questions--children's idea in their own words.

(3) Randomly_adjectives placed paired opposites covering all characteristics of the environment, thermal, visual and aural (from this an overall picture of the environment can be built up).

(4) Ranked or graded questions on specific characteristics of the visual environment on 4- or 5-point scales covering daylight, contrast, sunshine and glare, color, shadow.

\subsection{Social evidence}

Sociometric studies based upon Moreno, Northway, and Bronfenbrenner were made in each school to identify the social relationships and children's views of status to ascertain the influence of such relationships upon choice of groupings and position. (Ruys, 1970)

\subsection{Personality characteristics}

Junior Eysenck Personality Tests were made to measure neuroticism and extraversion in the children to see if there might be relationships between such choice and characteristics of position with changing environmental qualities.

\subsection{Color vision tests}

All children were examined for color perception defects by the Ishihara Test for possible influence upon answers to certain questions.

\subsection{Physical survey}

Each school was investigated to enable comparison to be made between expressed opinion and position choice with photometric measurements, physical characteristics and other information about the environment. The data is related where relevant to each grid centre at $700 \mathrm{~mm}$ above floor level in conformity with a standard procedure, values being normalized to a common basis, and includes the following:

-Elevations, plans and sections of the relevant areas of site information and each school, to scale 1/100 and to $1 / 20$ for position studies

-Daylight measures for each grid location as a sky factor applying the TNO lens

-Information for calculation of reflected light internally

-Sunlight: possible times of sunshine in school hours for each equinox and solstice

- Scalar/Vector angle of vector and ratios for each grid location reference point

-Glare from windows at two locations in each space, viz. facing parallel to windows and main windows

-Luminance ratios of reading task against general and immediate background for representative positions

- Reflectivity and Color of surfaces

-Artificial light: planar luminance at each grid location. Only one school added artificial light as a supplement to daylight constantly. 


\subsection{Method of analysis of survey information}

The behavioral evidence is examined by a comparison of the numbers of children in relation to their movement and disposition between locations adopted in the teachers' presence (location A) and those with freely chosen in the teachers' absence (location B), as shown in the following example, with similar evidence examined from the whole sample. Statistical tests are used to evaluate the ratios of children found, to identify effects and to correlate factors in the forming of groups. The attitudinal evidence is similarly examined by statistical methods and by examination of freely expressed views. Social evidence is examined by personality measures and socio-metric methods by Sybil Eysenck methods. Different alternative hypotheses were examined by a mixture of the above methods in a process of elimination of possible effects.

\section{Results}

Analysis of collected evidence for all schools with analysis of one school as an example in the investigation is given.

\subsection{Behavioral evidence}

The school depicted in Figs1-8 is similar to the majority in the sample. It is of new system design and has two connected areas with internal roof lights and peripheral windows. It has a suitable 'home' area (Figs. 4 and 8) good access to external play areas of pleasant view and a comfortable 'home' area. Furniture is modern. At the time of investigation the number of children was below design complement.

Figure 4 illustrates the distribution of children with the teacher present (location A). One place is fairly evenly occupied with sexes evenly mixed.

Figure 5 indicates the distribution without the teacher and free choice of place offered (location B). Children are now widely scattered with some concentration in home area and window areas. The sexes are mainly separated.

Fig 6 indicates the movement from A to B. Of 29 children, eight moved inwards (three indecisive) and 18 moved outwards towards windows. Although this is not completely beyond acceptable limits of chance being a small sample, if we regard the ratio of movements of a similar nature from nine schools in the investigation (deleting two where little movement occurred), then 192 out of 297 children moved, of whom twice as many moved outwards as inwards a probability of $p=0.00032$, two-tailed Binomial test. Chance played a small section in the selection. Less movement take places in older buildings and in those of higher density.

But lack of movement may also indicate a preference for location. Figure 7 shows the disposition in location B (free choice) and the ratios of children in 'inside' vs. 'outside' locations in relation to distance from the main windows (a fair division of space being assumed). Of 39 children, 30 chose outside locations. A Binomial test shows the probability of this taking place to be $p=0.0014$, two-tailed. If the same methodology is applied to all schools in the investigation then it is found that 227 out of 353 children chose outside positions near windows in location B $(p<0.00006$, two-tailed). In fact every school save one indicates this tendency in some measure and it is most unlikely to be because of chance. Scrupulous fairness was shown in drawing the line between 'outside' and 'inside' location in relation to windows. If the same comparison is made for location A (no specific offer of free choice of place and teacher present) then only 181 out of 331 children chose 'outside' locations-a ratio which could happen by chance fairly readily ( $p=0.099$, two-tailed).

A Spearman rank correlation coefficient rs, between the proximity to the windows and the number of children calculated in the sample school gives: $r_{a}=0.75$ the significance level of which is $p=0.05$, one tailed for $\mathrm{N}=8$ and in most of the schools same correlations are found individually. For all the schools taken together $r_{s}=$ 0.887 for which $p=0.05$, one-tailed for $\mathrm{N}=6$.

There are more children the nearer the windows. The correlations are weakest in former and sometimes cramped schools with higher sills and smaller windows. In some schools there was some movement to home regions with their more suitable seats (Fig. 8) but the tendency is not indicated and certainly cannot compete with the 'outside' locations close to windows. Different factors may be the cause of this priority, such as the view out, the amount of daylight, the arrangement of furniture, particularly seats, social factors other, environmental factors, or even the personality characteristics of the children. Each of these can be proved.

(1) The amount of daylight as a possible effect on behavior

This was tested closely in several ways. In the sample school a Spearman rank correlation between the children's number in 5 grid and the daylight level for the grid gives $r_{s}=0.423$ for $\mathrm{N}=14$ which is close to an suitable significance level of $p=0.05$. A similar correlation for all the elementary schools combined gives $r_{a}=0.252$ for $\mathrm{N}=143$ for which $p=0.005$ which is well beyond the level set. 
In itself this does not prove that one item is causative of the other but it suggests that this may be an essential relationship deserving further investigation. In the sample school the daylight level over the grids changes from 1.5 to $11.6 \%$ daylight factor with a mean level of $5.01 \%$. Over all elementary schools the daylight levels change greatly, the mean level changing from 2.33 to $9.7 \%$, but it is the variation in each school which is significant. The possible relationship between the amount of daylight and children's free choice of location may be studied more closely by taking advantage of the groups already formed.

Group 1: children in 'outside' locations

Group 2: children in 'inside' locations

These groups may be examined in a $2 \times 2$ contingency table with the numbers of children found in low and high daylight locations.

The groups may be compared using a $\chi^{2}$ [a statistic calculated from observed information] test to find out whether or not the amount of daylight is important in their formation. Each school was tested individually in this manner and in fact most of them show that daylight is likely to show such influence (if the significance level is set at $\alpha=0.05$ ).

When all the schools are taken together Table 1 appears. If the null hypothesis shows that there is no difference between the groups in the numbers of children found in low and high daylight regions and the alternative hypothesis is that there is such a difference thus $\mathrm{d} f=1$ the probability that $\chi^{2}=93.5$ is equal to or larger than chi square $=\mathrm{I} 0.83 \mathrm{t}$ is $p=0.001$. Obviously $\chi^{2}$ is significant for beyond the level of significance set of $\alpha=0.05$.

The null hypothesis might be rejected and the result is that the level of daylight does exert an effect in the formation of the groups and thus upon position choice.

A similar research with two groups composed of 'popular' grids (i.e. those with above the mean number of children in them) and 'unpopular' grids (those with less than the mean number) shows that the amount of daylight seems to be the cause of the popularity of such groups.

In 4 of the schools however such relations are weak. These are mostly the older buildings with poorer windows. But one modern building does not in accordance with this pattern. The important difference in the design of this school lies in its centrally located clerestory windows which are additional to its normal windows in the walls (Fig. 9). The only school with fixed supplementary artificial lighting indicates no difference from normal schools in the above relations. Suitable 'home' regions, where found, exerted some attraction but it was much less than for the windows. An even more rigorous examination of the relationship is possible. In spite of provision of internally placed clerestories or roof lights, in general more daylight is found in 'outside' regions than 'inside' regions. But from the full sample it is possible to make two groups of schools therefore:

Group 1: schools with daylight in 'outside' regions

More than twice that found in 'inside' regions

Group 2: schools with daylight in 'outside' regions

Less than twice that found in 'inside' regions.

A prediction that most of the children will be found in 'inside' areas in Group two than in Group one would be consistent with a hypothesis that the amount of daylight defines the positions adopted by the children (One-tailed prediction). The considered level of significance was at $\alpha=0.05$. A $\chi^{2}$ test of these groups in a $2 \times 2$ contingency table for the numbers of children opting for each category in a free choice condition gives $\chi^{2}=$ 2.528 for $\mathrm{N}=353$. The probability under $H o$ (the null hypothesis) that, $\chi^{2}=2.528$ is greater than or equal to chi square $=2.71$ for $\mathrm{d} f$ (degree of freedom $)=1$ is $p=0.05$, one-tailed. This does not exactly reach the significance level set but is very close to suggest an improved experiment if possible. The three schools forming Group 2 are as follows: a modern school with very good windows but also with interior clerestories giving high light in the interior (Fig. 9), one old school with high level windows entering light into the interior and one modern school with internal roof light and windows in adjacent walls. Only the school with clerestories has more children in the 'inside' than the 'outside' areas. If the test is repeated Group two being the one school with clerestories and Group one being all the other ten schools and the same prediction is made the result is as shown in Table 2. (Fig. 9)

The probability under Ho that $\chi 2=7.15$ is greater than or equal to chi square $=6.64$ under $d f=1$ is $p=0.005$, one-tailed. Ho may be rejected and the result is that daylight is the motive force in the formation of the considered groups. If the whole of this behavioral evidence is considered together the result should be that fenestration, behavior and daylight are closely associated, but it would be necessary to eliminate other possible effective factors from consideration before making a definite conclusion. 


\section{1(a) The Occupiers` Perimeter migration}

The occupiers ' perimeter migration in rooms has been found in certain places such as restaurants where central positions are often avoided. Does this phenomenon exist in schools and may it account for the noticed behavior?

All the schools in the investigation were theoretically divided into central zones and perimeter on an equitable basis and the numbers of students in each in situation B (free choice) were counted. The perimeter length and their density per $\mathrm{m}^{2}$ for each zone were also measured. There was slight difference between the zones for all these aspects, a slight but not significant preference being shown for the central zone. Meanwhile perimeter migration is not an influence on behavior in this survey.

\section{1(b) The Furniture's Position}

Furniture might be suggested as an influence on position, particularly seats and chairs. This might well be true where the number of positions available is limited or desks and chairs are fixed to the floor or heavy. But these limitations are found in this study only in an old school. In all other cases the furniture was very light and easily moved by the children and they were used to doing so to suit their requirements, particularly in respect to seats and chairs. On the assumption that chairs were movable, the available positions at tables or desks considerably exceeded the number of children who needed them. For all schools together the positions available 'outside' and 'inside' as defined is not significantly different both in situations A and B (Table 3).

But the number of children found in 'inside' and 'outside' areas, while not significantly different in situation A with the teacher present, is obviously different in situation B (free choice), viz. 'inside' 126, 'outside' 226 (a two-tailed probability of $p=0.00006$ or less, Binomial test). Generally chance might be ruled out and the result is that the positions of the children do not reflect the furniture arrangement.

The teacher is the only influencing factor present in situation A which is absent in situation B. In fact the teacher's presence obviously has effect on their choice while the furniture in not an influence. A more effective test (Yates $\chi^{2}$ test) was set to a $2 \times 2$ contingency table (Table 4 ).

Ho shows that there is not any differences between the two groups, places available and places chosen in the numbers found in 'inside' and 'outside' positions, and the alternative hypothesis is that there is such a difference and greater numbers might be found in 'outside' areas in the second group (one-tailed). The significance level was set to be at $\alpha=0.05$. The probability under $H o$ that $\chi^{2}=11.295$ is greater than or equal to chi square $=10.83$ for $\mathrm{d} f=1$ is $p=0.0005$ (one tailed). Ho may be rejected and the result is that the availability of places does not give the choice of position. Every school was examined separately in a similar way with much the same conclusion, save in elder crowded schools or those having heavy furniture and in one modern school, viz. that with the central clerestories where most tests revealed differences from the normal. Definitely furniture position is not influencing the children's choice of position.

\section{1(c) Effectiveness of the view}

Does the view provided by the windows make the children sit close to them? If this hypothesis is true then in schools with a better view out (and an interesting or pleasant prospect) it is likely that children will take positions which provide the best view out at least in situation B (free choice). 'Outside' positions as defined could be likely to offer better quality views than 'inside' positions. The schools in the study were arranged in two groups (Table $5)$.

Group one: with a good view out.

Group two: without a good view out.

The null hypothesis $H o$ would show that there could be no difference in the proportions in which the students in the two groups opt for inside' and 'outside' positions, the alternative hypothesis being that indeed more children could be found in Group one in 'outside' positions. Significance level may be set to be at $\alpha=0.05$, one tailed. One school was omitted from the count as not classifiable on 'view'. The probability under $H o$ that $\chi^{2}=0.12$ is greater than or equal to chi square $=0.064$ is $p=0.40$, one tailed and the null hypothesis should be accepted. View out appears to have no influence on position choice.

Even more exact classification of the groups was tried with Group one being all schools and Group two only schools with a very poor view out but still no considerable difference was found. This does not necessarily mean that students do not like a view out (later evidence defines that they do) but rather that view out is not influencing the position choice. The possible interaction between view and daylight as determinants of position chosen by the children was further investigated by analysis of variance. Ratios of 'outside'/total frequency of students were drawn from each of ten schools in 4 categories as in Table 6. 
The 'Anova' shown in Table 7 is the result of a two-factor factorial experiment with each qualitative factor at two levels with 10 replicates. For tables for the $\mathrm{F}$ test of $1 \mathrm{df}$ against 36 , a value of 13 results in a significance level of $p=0.001$. Therefore the rows (daylight) show a significant effect while the others do not. The result is that daylight does influence the choice while view does not and there is little interaction between the factors.

\subsection{Attitudinal evidence}

The questionnaire on children's attitude showed the following results (taken from all schools together). Most children like their classrooms and school, girls being more positive than boys in their opinion.

Indirect queries about dislikes and likes in the classroom give the following ranked preferences, the individual schools showing markedly similar responses to the whole sample. (Table 8)

(a) Likes

Of individual factors 'the big windows' are of the most frequently-mentioned likes of the students, but teacher, paintings and pictures, the large space, are prominently featured.

(b) Dislikes are obviously fewer and mostly concern faults in usually favored items, e.g. dull, dirty, high windows, thermal discomfort, and uncomfortable furniture. The differences in the responses from children in 'inside' and 'outside' positions are small. Despite 'inside' groups were relatively far from the windows nevertheless the windows are still important to them. Almost all children want to see out and give as their reasons: to see what is going on, to see nature, flowers, grass, animals, weather, light and sun. Dislikes include too much light, sun in the eyes, bad view, distraction, noise. To see out is less important to boys than girls, and there are significant differences between them. Most children liked sunshine, even those in 'inside' groups.

Colors of the room are important to the students, there being a significant difference between 'inside' and 'outside' groups. Color may affect their position choice. Colors near windows are somewhat more vivid due to greater illuminance.

The adjective test shows interesting evidence of the children's attitude to all the environmental issues, outstanding characteristics selected by the children describing the atmosphere for most schools as being the following: dry, hot, fresh, bright, light, colorful, convenient, clean, tidy, happy, comfortable, a little noisy, busy, rather low (ceiling height). 'Inside' and 'outside' groups showed significant differences considering a few factors, mostly intangible or thermal, suggesting that these factors may influence position choice. The factors are: interesting, comfortable, happy, and draughty. The students selected the adjectives from a given list.

Queries about the environment on five-point scales from 'too little' to 'too much' mostly seem to result in a choice near the centre of the scale (just right) in spite of noticeable differences in the rooms.

Contrast concerning the task. Measured luminance for book, desk, and floor, showed a ratio in the sample of about 3: 1: 3 (pale floor). 'Inside' and 'outside' groups differ in their idea about contrast, those in 'inside' skewing towards 'too bright'. Contrast may have some effects on position choice.

Glare in the room, another way of contrast measurement, was indicated in the sample as 'a little bright' (idea) both for 'inside' and 'outside' groups. The measured glare index for both rear and front positions in the room were above the levels recommended for schools but agree with Hopkinson's opinion as between 'just uncomfortable' and 'just acceptable'. Some difference was defined in the views of the 'inside' and 'outside' groups on glare but the difference was not significant. Again scalar/vector ratios for positions representing 'inside' and 'outside' groups showed noticeable difference by measurement but very little difference in terms of opinion. Other factors were considered and compared with opinion but only two factors appeared to influence position choice (apart from daylight) and these are contrast conditions and glare. In general, the attitudinal evidence mainly supports the evidence derived from the children's behavior. (Fig. 10)

\subsection{Socio-metric studies and Social factors}

Socio-metric investigations of the schools established their social structure (as desired by the students) which was compared with their choice of position and their responses to questions. 'Cliques' (that is groups desiring mutual association) and 'Stars' (that is children of high status in the eyes of their fellows) were identified. An obvious division into two major groups, viz. girls and boys, is noticeable when they are free to choose position, and 'stars' are found close to the windows. Neither of these phenomena occur in situation 'A' when the teacher is present. In situation 'B' the proportion is twenty out of twenty six stars in 'outside' positions. The estimated probability of this occurring by chance is $p=0.0108$, two-tailed, thus the choice is a deliberate one. When the teacher is present his influence on position is considerable. There is little evidence of physical relations between 'stars' and the members of their clique nor do 'stars' act as focal points either for children generally or for their 
own clique. A Spearman rank correlation $r_{s}=0.208$ that is significant at the $p=0.005$ level, one-tailed (Kendall test for $\mathrm{N}=166$ ) is defined between status and proximity to windows for boys (ten schools) but not for girls though there is a positive correlation. Cliques have some effects on groupings but not in a clear way. Pairing and to some extent formation of trios is obvious. There is not any noticeable difference between girls and boys in their options for 'outside' or 'inside' positions and girls and boys together opt strongly for 'outside' positions. The result is that social influence on seating choice is present but it is weak and cannot account for the general seating trends found. It is a lesser effect within a stronger one, a secondary pattern of behavior. Girls and boys show some noticeable differences in behavior but they are mostly of degree. The relationship between proximity to the windows and status of the children might be said to reinforce previous evidence that window positions are favored. No convincing evidence was detected (by analysis of variance) that social factors affected the responses given to queries.

\subsection{Personality tests}

The Sybil Eysenck personality tests gave scores for neuroticism and extraversion for all the children. These scores were divided into two groups, viz. 'low score' and 'high score' and the groups were compared with the numbers of children found in the categories 'inside' and 'outside' position, on the assumption that environmental stimulus was different for the two positions. No considerable difference was found between the groups. Either there is no relationship between these personality characteristics and visual stimulus, or the difference in stimulus is insufficient.

\section{Conclusions}

The general hypothesis is proven. Children in primary school, given a free choice without teachers' influence, opt to sit in positions near to windows. Their choice is influenced by some physical conditions such as crowding, poor windows or heavy old furniture, but the main effect is high daylight levels. Their attitudes, judged by queries, support these results strongly. They indicate strong regard for sunlight, windows, nature in different forms, and 'to see what is going on' (Fig. 10). Seeing out is very important though, it does not necessarily result in sitting at windows. They like comfort, especially thermal, and object to damage and dirt in the building particularly to windows. The effect of social structure is evident in pairing and sex segregation. High status children take preferred window positions but social cliques have little influence on the selection of window positions. These are lesser social effects within other more dominant influences. View out, furniture arrangement, perimeter migration and social issues are not major influences on choice of position, though in some cases they might exert secondary influence. Students in the primary age group could well develop attitudes to their school environment. The nature of this behavioral survey is not such as to offer an explanation for the attraction which daylight holds for most of the students, even if this were possible. One may speculate that the students ' previous experience of the benefits likely to arise from more daylight such as the likelihood of being able to observe better or to experience colors more vividly, coupled with the present stimulus, could be such as to induce a spontaneous movement towards the daylight.

\section{Architectural Implications}

The authors ' interpretation of these results would be that daylight and the design of roof lights and windows deserve renewed attention from school designers, but in balance with other powerful effects upon design. The general tendency towards deep plan schools for organizational and economic reasons suggests the use of any of the walls for renewed attention and fenestration purposes to internally placed clerestories or other openings. The attraction that windows hold for children could be used to encourage a more even use of floor space, even in internal positions, by careful placing of internal clerestories, maybe accompanied by some variation in floor levels (storage below with students' space above in a partial two-storey arrangement). This could allow students to see their teachers, eye-to eye for once. And there is more space in the height of present schools far up beyond the use of the children. But of course measures would require to be taken to avoid glare and excessive sun heat, with very careful attention being given to energy balance. The desire expressed for comfort could justify improved design of furniture by making it a little softer and more easily moved with the same improvements to soft floor seating and floor finishes. Improved flexibility in the use of space may suggest some flexibility in positioning of windows, possibly by interchangeable panels with windows that could be reconciled fairly readily with the framed types of structure likely to arise from other needs. Space does not allow further discussion here but the main contribution of the present results lies in the proved positive attraction of windows of different types as a design generator, including a more serious attempt to utilize roofs of predominately one-storey buildings as light sources. But this might not be taken to imply the provision of very big glass areas, but rather a 
more efficient use of openings both as light sources and of subjective attraction to the students. Nor should the attraction of nature for the students be disregarded.

\section{References}

Brubaker, W.C. (1998). Planning and Designing Schools. New York: McGraw-Hill.

Canter. D. (1974). Psychology For Architects. Applied Science, London, p.v.

Dilouie, C. (1996). Personal vs. automatic. Architectural Lighting, 10, pp. 53-61.

Hopkinson. G. (1963). Architectural Physics--Lighting, p. 201 ft. HMSO, London.

Laumann, K., Gärling, T., \& Stormark, K. M. (2001). Rating scale measures of restorative components of environments. Journal of Environmental Psychology, pp. 28-54.

Ruys, D. (1970). Windowless offices, Unpublished master's thesis. University of Washington, Seattle, Washington.

Taylor, A., Aldrich, R.A., \& Vlastos, G. (1998). Architecture can teach. In Context, 18, P. 31.

Tuaycharoen, N. \& Tregenza, P.R. (2007). View and Discomfort Glare From Windows. Lighting Res. Technol, pp. 170-181.

Young, E., Green, H.A., Roehrich-Patrick, L., Joseph, L. \& Gibson, T. (2003). Do k-12 School Facilities Affect Education Outcomes? Tennessee: The Tennessee Advisory Commission on Intergovernmental Relations.
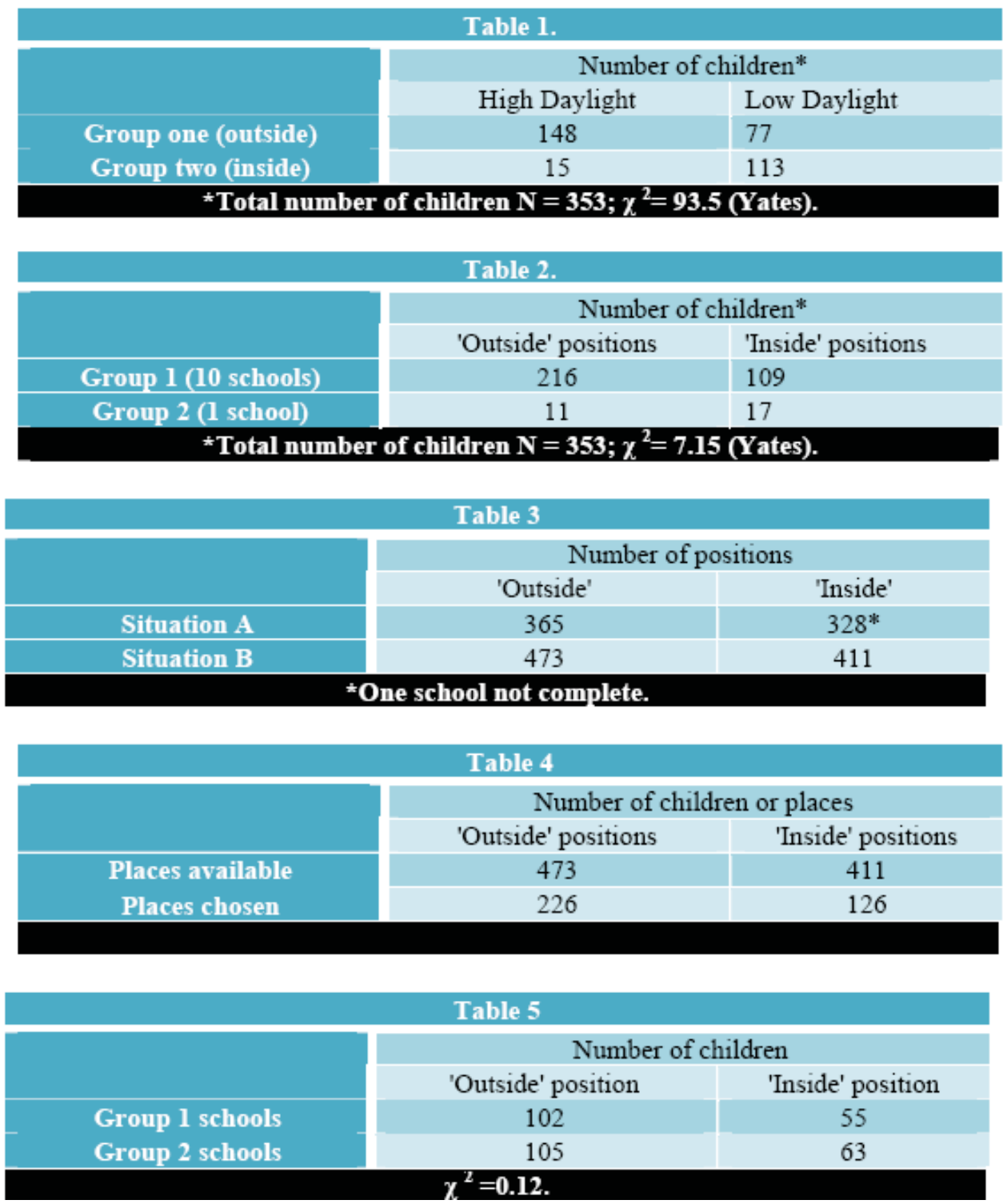


\begin{tabular}{|c|c|c|}
\hline \multicolumn{3}{|c|}{ Table 6} \\
\hline \multirow{4}{*}{ Areas of high daylight } & Schools with good view & Schools with poor view \\
\hline & $0.769,1.00,0.750,0.392$ & $0.634,1.00,0.567,0.571$ \\
\hline & $1.00,0.558,1.00,0.750$ & $0.705,0.888,0.593,1.00$ \\
\hline & $0.809,1.00$ & $0.625,1.00$ \\
\hline \multirow{2}{*}{ Areas of low daylight } & $0.769,0.590,0.750,0.363$ & $0.634,0.272,0.567,0.500$ \\
\hline & $\begin{array}{c}0.392,0.227,0.558,0.347 \\
0.750,0.571\end{array}$ & $\begin{array}{c}0.705,0.500,0.593,0.480, \\
0.625,0.100\end{array}$ \\
\hline
\end{tabular}

\begin{tabular}{|c|c|c|c|c|}
\hline \multicolumn{5}{|c|}{ Table 7 } \\
\hline Source & Sum of squares & $\mathrm{d} f$ & Mean square & $\mathrm{F}$ \\
\hline Rows (daylight) & 0.7074 & 1 & 0.707 & 18.85 \\
\hline Cols (view) & 0.0159 & 1 & 0.016 & 0.43 \\
\hline Interaction & 0.0001 & 1 & 0.0001 & 0.003 \\
\hline Residual & 1.3508 & 36 & 0.0375 & \\
\hline Total & $\mathbf{2 . 0 7 4}$ & 39 & \\
\hline
\end{tabular}

\begin{tabular}{|c|l|}
\hline \multicolumn{1}{|c|}{$\begin{array}{c}\text { Table 8 } \\
\text { Votes }\end{array}$} & \multicolumn{1}{|c|}{ Categorv* } \\
\hline 114 & Furniture and furnishings (contains many items) \\
\hline $\mathbf{6 4}$ & Windows and associated factors (blinds, light, sun, view, curtains) \\
\hline $\mathbf{5 3}$ & Pictures, paintings, drawings \\
\hline $\mathbf{5 1}$ & The large space \\
\hline $\mathbf{4 7}$ & Activity centers \\
\hline $\mathbf{4 3}$ & Library and books \\
\hline $\mathbf{3 4}$ & Teacher \\
\hline $\mathbf{2 1}$ & Modern design \\
\hline $\mathbf{1 4}$ & Television \\
\hline $\mathbf{1 3 - 8}$ & Other factors \\
\hline *Arranged in groups formed from answers in the children's own words. \\
\hline
\end{tabular}

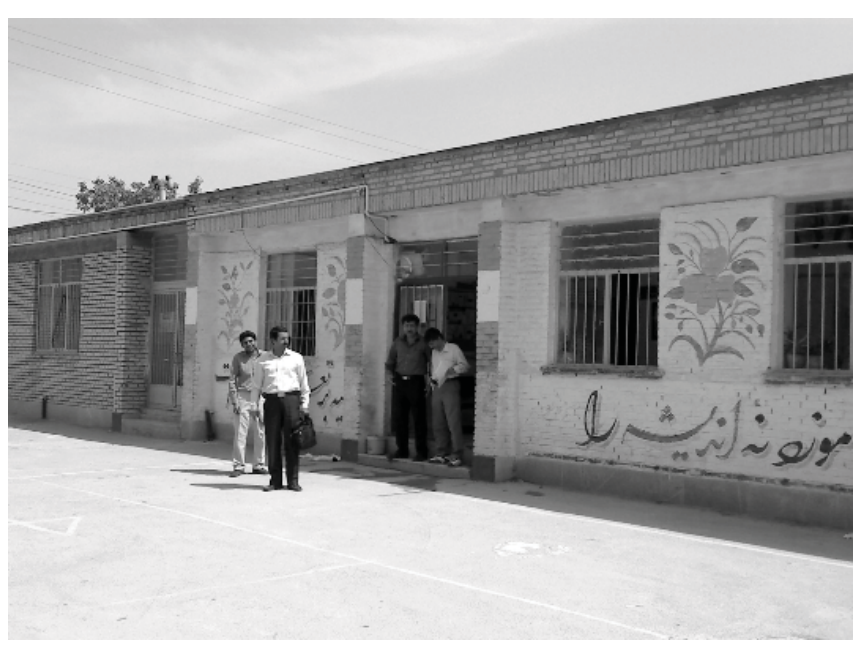

Fig. 1. Exterior view

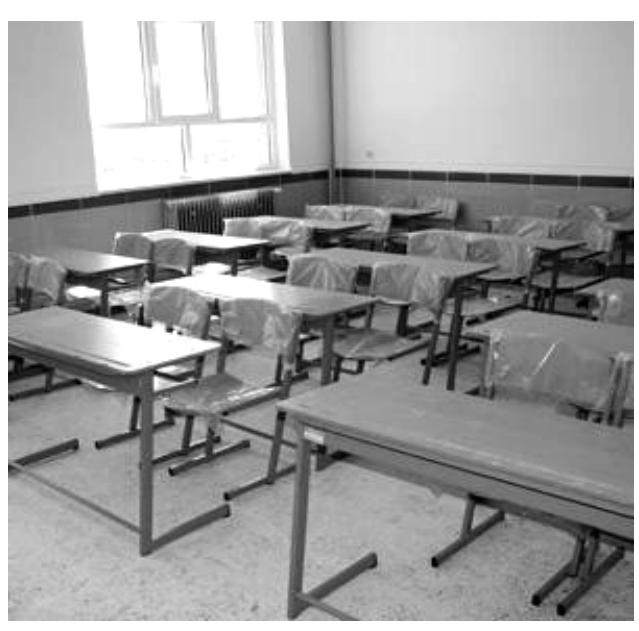

Fig. 2. Interior view 

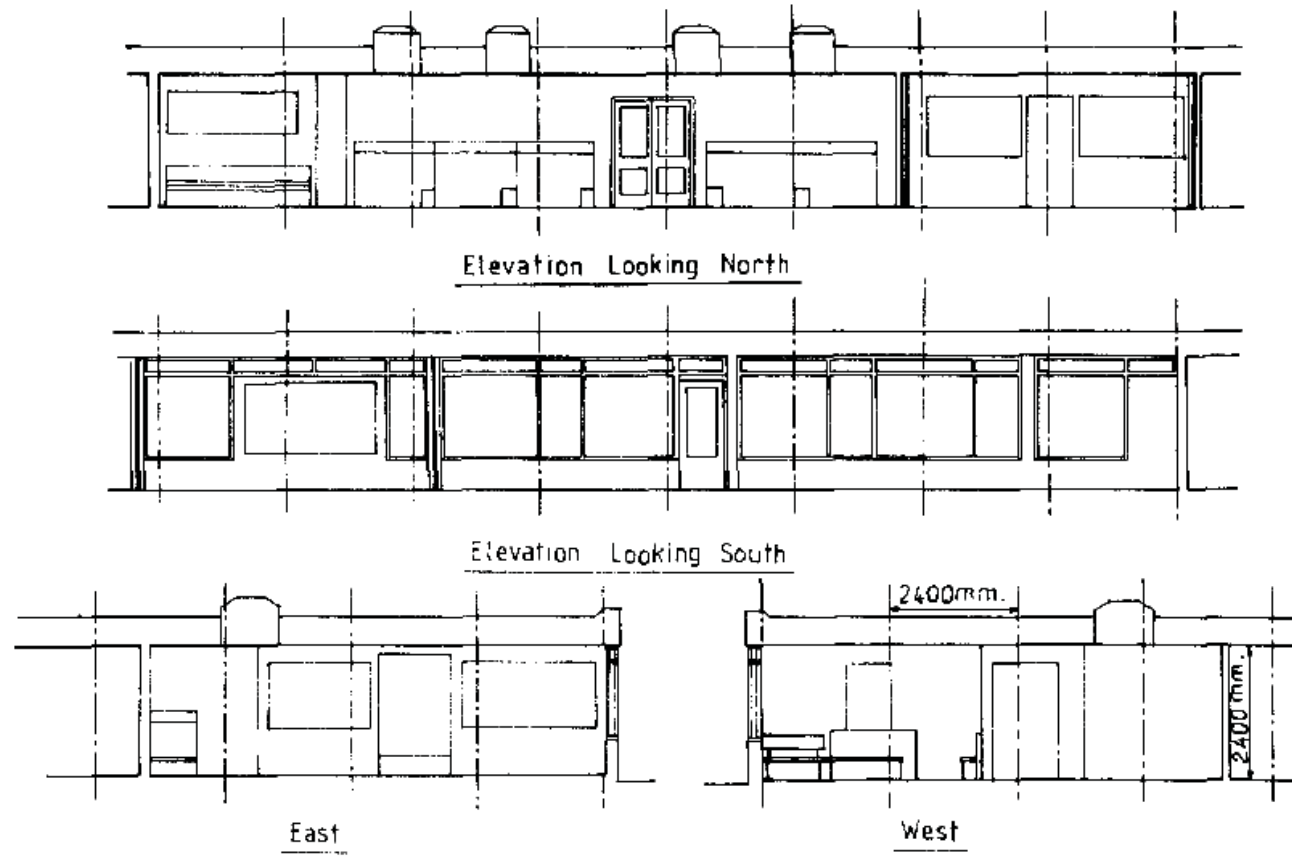

Fig. 3. Interior room elevations

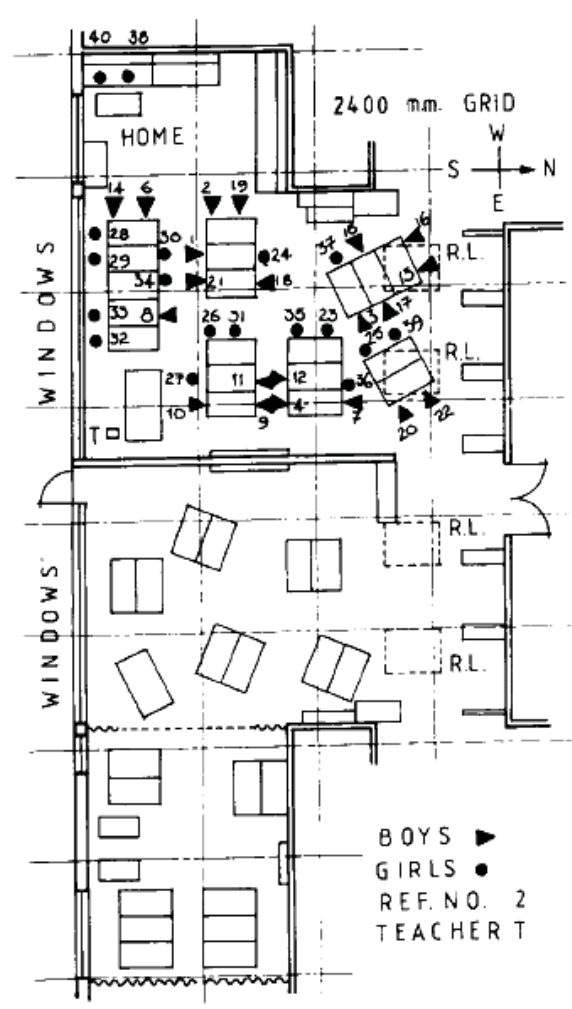

Fig. 4. Position of children in 'situation $A$ '.

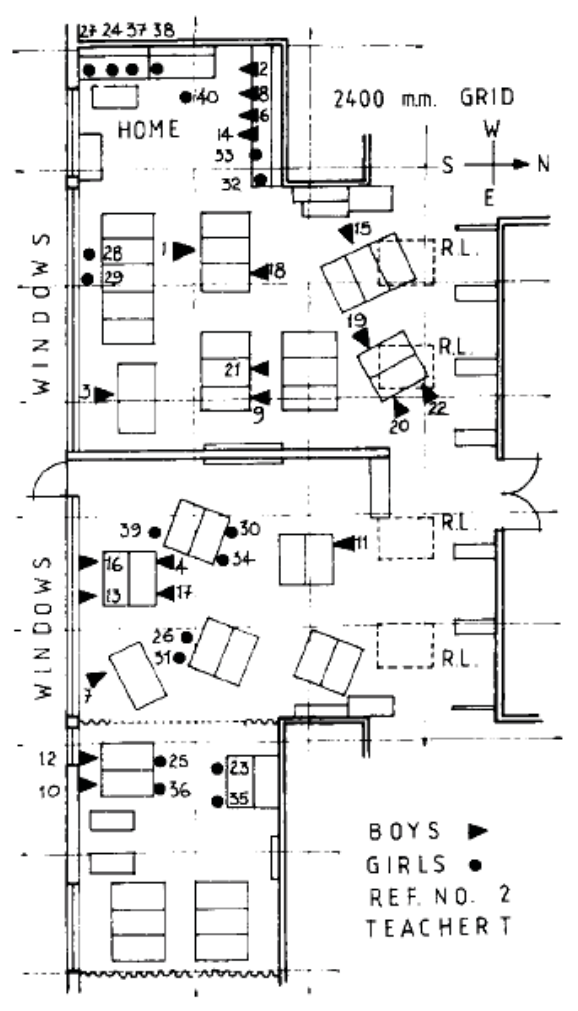

Fig. 5. Position of children in 'situation B'. 


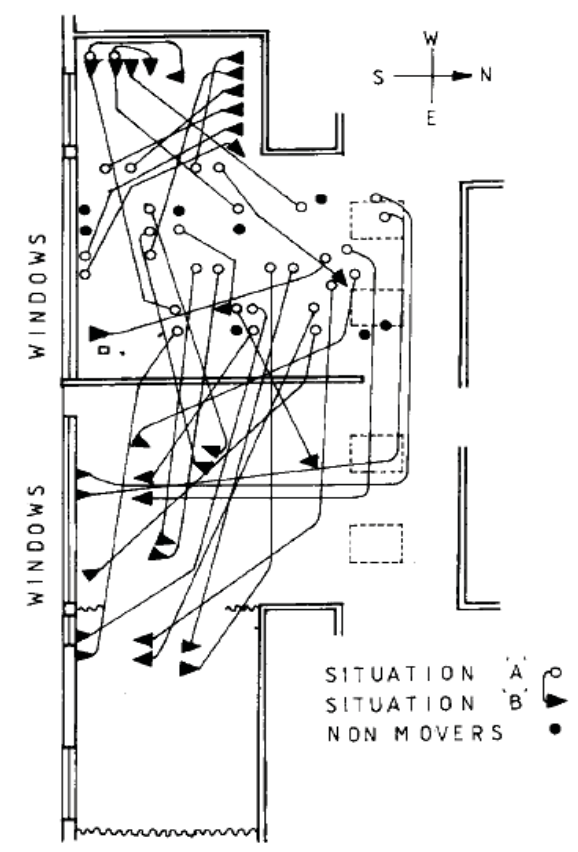

Fig. 6. Direction of moves from 'A' to 'B'.

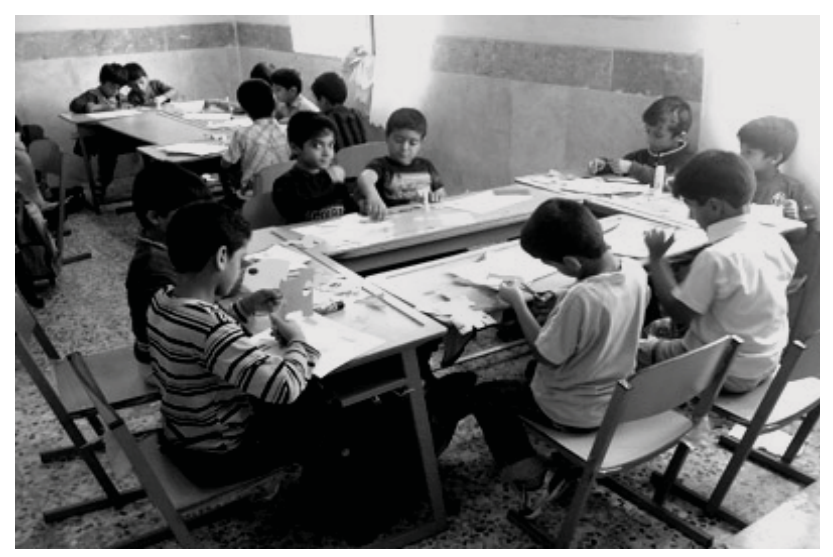

Fig. 8. 'Home' positions

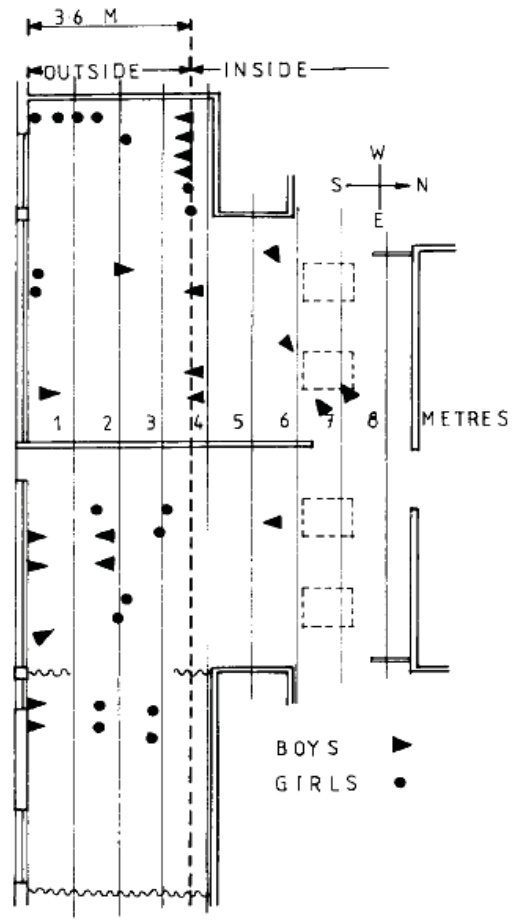

Fig. 7. 'Outside' and 'inside' positions in 'situation B'

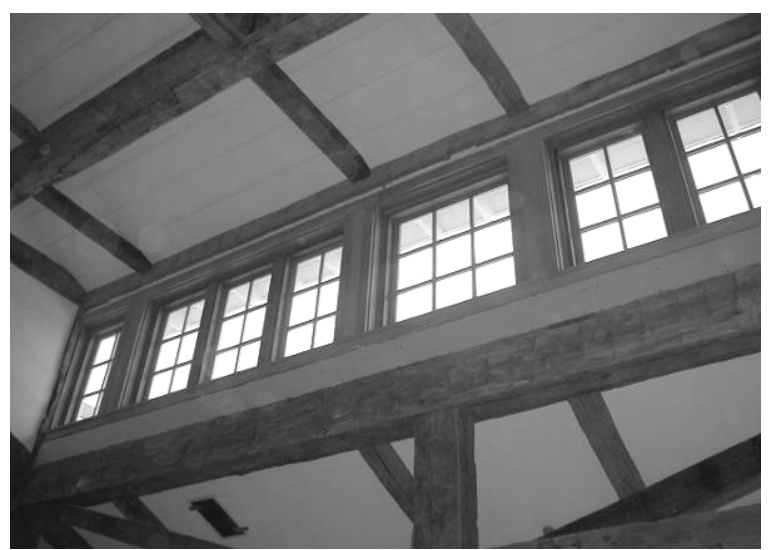

Fig. 9. School's clerestories

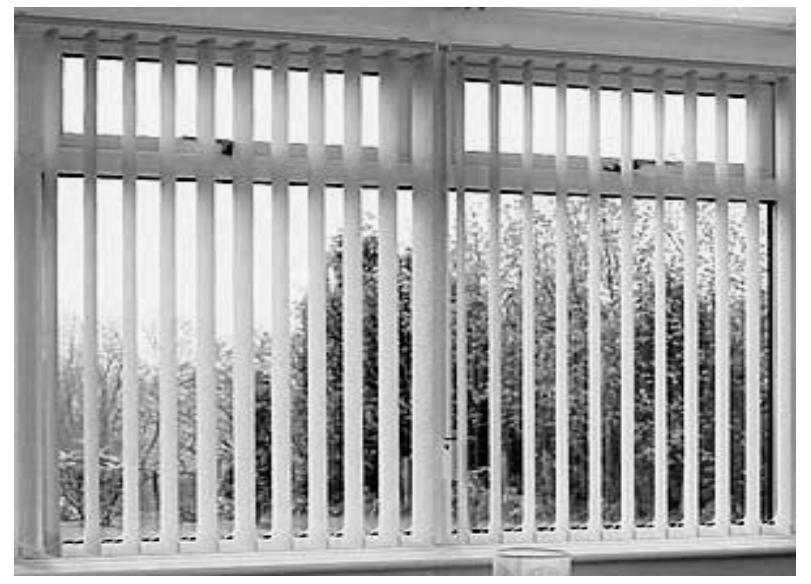

Fig. 10. View out through blinds 